\title{
Child-adult differences in whole blood lactate responses to incremental treadmill exercise
}

\author{
K Tolfrey and N Armstrong \\ PEA Research Centre, School of Education, University of Exeter, Exeter, UK
}

\begin{abstract}
The aim of this study was to evaluate whether fixed blood lactate reference values of 2.5 and $4.0 \mathrm{mmol} \cdot 1^{-1}$ corresponded to the equivalent intensity of exercise in prepubertal and teenage boys, and men. Twenty six prepubertal boys (mean(sd) age) 11.1(0.4) years), 26 teenage boys (mean(sd) age 14.1(0.3) years), and 23 men (mean(sd) age 22.4(2.7) years) gave informed consent to participate in the study. Oxygen consumption $\left(\mathrm{VO}_{2}\right)$ and heart rates (HR) corresponding to the 2.5 and $4.0 \mathrm{mmol} \cdot \mathrm{l}^{-1}$ fixed blood lactate reference values were used as the criterion measures during incremental treadmill exercise. At the $2.5 \mathrm{mmol} \cdot \mathrm{I}^{-1}$ level there were no significant differences $(P>0.05)$ in \% peak $\mathrm{VO}_{2}$ between groups. For both prepubertal and teenage boys the $4.0 \mathrm{mmol} \cdot \mathrm{l}^{-1}$ lactate level represented a higher mean \% peak $\dot{V O}_{2}$ than for the men $(P<0.05)$. The prepubertal and teenage values were again not significantly different $(P>0.05)$. Factors other than maturation during puberty influence blood lactate responses to exercise.

(Br J Sports Med 1995; 29 : 196-199)
\end{abstract}

Keywords: blood lactate; prepubertal; teenage; men; boy

The use of the $4.0 \mathrm{mmol} \cdot \mathrm{l}^{-1}$ fixed blood lactate reference value to monitor and assess endurance performance in adults has received considerable attention. ${ }^{1}$ Although suitable for use with adults, the $4.0 \mathrm{mmol} \cdot \mathrm{l}^{-1}$ fixed blood lactate reference value may not be appropriate for children because it corresponds to an almost maximal, rather than submaximal, effort. ${ }^{2}$ This finding is, however, based on only a few studies, all of which differ methodologically. The maximum lactate steady state (MLaSS), the point of equilibrium between lactate production and removal, and $4.0 \mathrm{mmol} \cdot \mathrm{l}^{-1}$ lactate do not correlate highly in children. ${ }^{3}$ However, oxygen consumption $\left(\dot{\mathrm{V}}_{2}\right)$ and heart rate (HR) corresponding to $2.5 \mathrm{mmol} \cdot{ }^{-1}$ in children are not significantly different from those measured at the MLaSS. ${ }^{3}$ For this reason, $2.5 \mathrm{mmol} \cdot \mathrm{l}^{-1}$ lactate in children may be used in a similar manner to the $4.0 \mathrm{mmol} \cdot l^{-1}$ value in adults.

Direct comparisons of $\dot{\mathrm{VO}}$, and heart rate responses corresponding to the 2.5 whole blood lactate values between children and adults do not appear to be available. Studies designed to compare children and adult physiological responses at the $4.0 \mathrm{mmol} \cdot \mathrm{l}^{-1}$ level

Address for correspondence: Dr K. Tolfrey, The Manchester

Metropolitan University, Department of Sport and Environmental

Science, Division of Sport Science, Hassall Road, Alsager, Stoke-on-

Trent, ST7 2HL, UK. have only measured heart rate, and not $\mathrm{VO}_{2} \cdot{ }^{24}$ Interstudy comparison between children and adults at submaximal exercise intensities are difficult due to differences in protocol, lactate sampling and assay techniques. ${ }^{5}$

Only one study to date has examined lactate responses to exercise with progression through the five stages of maturation identified by Tanner ${ }^{6}$; Williams and Armstrong ${ }^{3}$ failed to identify any significant differences in lactate response across the maturity groups. Conversely, using Tanner' ${ }^{6}{ }^{6}$ indices, Wirth et al. ${ }^{7}$ classified 25 boys into prepubertal, pubertal, and postpubertal groups. They reported that blood lactate concentrations following cycling exercise at $70 \%$ peak $\dot{\mathrm{VO}}$ increased significantly with increasing maturity. The influence of maturation on children's blood lactate response to exercise is equivocal. ${ }^{378}$

The aim of this study was to evaluate whether fixed whole blood lactate reference values of 2.5 and $4.0 \mathrm{mmol} \cdot \mathrm{l}^{-1}$ correspond to the equivalent level of exercise in children and adults; and also to see if differences existed between groups of boys classified as prepubertal and teenage. This information could be important when recommending optimal training intensities and evaluating children's exercise endurance capacity.

\section{Methods}

\section{Subjects}

Twenty six prepubertal boys, mean(sd) age 11.1(0.4) years, and 26 teenage boys, mean(sd) age 14.1(0.3) years, were pair matched on the basis of mass related peak $\dot{\mathrm{VO}}_{2}$. An adult group of 23 men, mean(sd) age 22.4(2.7) years, with similar mass related peak $\mathrm{VO}_{2}$ scores were drawn from an active group of university students. Institutional ethics approval for the project and written informed consent from all subjects, including parental/guardian consent for the boys, was obtained. Mean physical characteristics for each subgroup are shown in Table 1. Subjects were familiar with all test procedures before actual testing.

\section{Measurement of peak $\dot{\mathrm{VO}}_{2}$}

Peak $\dot{\mathrm{V}}_{2}$ was determined via a discontinuous, incremental treadmill test, comprising 3 min stages of increasing intensity. ${ }^{9}$ Following a $5 \mathrm{~min}$ warm up the groups of subjects began the tests at the following belt 
Table 1. Physical and physiological characteristics of the subjects

\begin{tabular}{|c|c|c|c|}
\hline Variable & $\begin{array}{c}\text { Prepubertal } \\
(n=26)\end{array}$ & $\begin{array}{l}\text { Teenage } \\
(n=26)\end{array}$ & $\begin{array}{c}\text { Adult } \\
(n=23)\end{array}$ \\
\hline Age (years) & $11.1(0.4)^{\mathrm{a}}$ & $14.1(0.3)^{b}$ & $22.4(2.7)$ \\
\hline Height $(m)$ & $1.44(0.04)^{a}$ & $1.63(0.09)^{b}$ & $1.77(0.06)$ \\
\hline Mass (kg) & $34.3(3.9)^{\mathrm{a}}$ & $49.5(8.9)^{b}$ & $76.7(9.4)$ \\
\hline Peak vi $\mathrm{O}_{2}\left(1 \cdot \mathrm{min}^{-1}\right)$ & $1.82(0.22)^{a}$ & $2.60(0.47)^{b}$ & $4.18(0.50)$ \\
\hline $\begin{array}{l}\text { Peak VO } \\
\left(\mathrm{ml} \cdot \mathrm{kg}^{-1} \cdot \min ^{-1}\right)\end{array}$ & $53(6)$ & $53(5)$ & $55(4)$ \\
\hline $\begin{array}{l}\mathrm{HR} \text { at peak VO } \\
\left(\text { beats } \cdot \min ^{-1}\right)\end{array}$ & $202(7)^{c}$ & 201(10) & 195(8) \\
\hline $\begin{array}{l}\text { Lactate at peak } \dot{\mathrm{VO}}_{2} \\
\left(\mathrm{mmol} \cdot \mathrm{l}^{-1}\right)\end{array}$ & $4.5(1.5)^{\mathrm{a}}$ & $5.8(2.1)^{b}$ & $8.7(1.9)$ \\
\hline
\end{tabular}

All values are mean(s.d.).

a Significantly different from teenage and adult groups $(P<0.05)$;

b Significantly different from pre-pubertal and adult groups

$(P<0.05)$; ${ }^{c}$ Significantly different from adult group $(P<0.05)$.

speeds with no incline: prepubertal $1.94 \mathrm{~m} \cdot \mathrm{s}^{-1}(7 \mathrm{~km} \cdot$ $\left.\mathrm{h}^{-1}\right)$, teenage $2.22 \mathrm{~m} \cdot \mathrm{s}^{-1}\left(8 \mathrm{~km} \mathrm{~h}^{-1}\right)$, adult $2.78 \mathrm{~m} \cdot \mathrm{s}^{-1}$ $\left(10 \mathrm{~km} \cdot \mathrm{h}^{-1}\right)$. The speed was held constant and the gradient raised for each stage subsequent to a belt speed of $2.78 \mathrm{~m} \cdot \mathrm{s}^{-1}\left(10 \mathrm{~km} \cdot \mathrm{h}^{-1}\right)$. Exercise stages were separated by a maximum of $90 \mathrm{~s}$ for blood sampling. Expired air was monitored continuously throughout each stage using a computerized on-line system (Oxyconsigma, Mijnhardt B.V., The Netherlands) which was automatically calibrated according to the manufacturers' instructions before each test. End of stage $\mathrm{VO}_{2}$ and peak $\dot{\mathrm{VO}}_{2}$ values were determined from the last $30 \mathrm{~s}$ of each stage. Heart rate was monitored using a Rigel (Morden, UK) electrocardiogram and recorded at the end of each stage. A measure of peak $\mathrm{VO}_{2}$ was accepted if: (1) the heart rate levelled off before the final exercise intensity or was $\geqslant 95 \%$ of age predicted maximum; and/or (2) if the respiratory exchange ratio was equal to or above unity. ${ }^{10}$ Peak $\mathrm{VO}_{2}$ is highly reproducible in children, ${ }^{10}$ and as reliable as $\mathrm{VO}_{2}$ max in adults, if the objective criteria given above are satisfied. ${ }^{1011}$

\section{Blood sampling}

Following each exercise stage, and upon termination of the test, capillary blood was taken from a thumb tip which had been wiped with alcohol. The first drop of blood was discarded and $25 \mu \mathrm{l}$ of free flow whole blood were collected in heparinized microvettes (Sarstedt CB300). These samples were immediately assayed in duplicate for lactic acid concentration using a YSI 2300 STAT lactate analyser (Yellow Springs Instruments, Yellow Springs, USA). The analyser self calibrated every 5 min using a $5 \mathrm{mmol} \cdot \mathrm{l}^{-1}$ standard; the maximum acceptable calibration error was $<2 \%$. The coefficient of variation of whole blood lactate measurement for the laboratory quality control was $2.85 \%$. It is acknowledged that the substantial changes in packed cell volume that can occur during a maximal test can influence lactate values determined from whole blood, but that the use of whole blood analysers in exercise science laboratories is widespread.

Oxygen consumption and heart rate responses were plotted against lactate concentration for each subject. Oxygen consumption and heart rate at 2.5 and
$4.0 \mathrm{mmol} \cdot \mathrm{l}^{-1}$ were determined by visual interpolation for each subject.

\section{Analysis}

The data were analysed using the statistical package for the social sciences (SPSS Inc, USA). Significant differences between group means were ascertained using one way analysis of variance (ANOVA) with subsequent Scheffé follow up where homogeneity of variance was established. Where homogeneity of variance was not established, Kruskal-Wallis ANOVA was used. ${ }^{12}$ Significance was assumed at $P<0.05$. Relationships among measures were examined using Pearson product moment correlation analyses. All data are presented as mean(sd).

\section{Results}

Oxygen consumption and heart rate responses at 2.5 and $4.0 \mathrm{mmol} \cdot \mathrm{l}^{-1}$ lactate concentrations are presented in Tables 2 and 3 respectively. For some subjects interpolation at one, or both, of the lactate values was not possible. Consequently, $2.5 \mathrm{mmol} \cdot \mathrm{l}^{-1}$ lactate analysis was based upon 21 prepubertal boys, 22 teenage boys,

Table 2. Oxygen consumption response at exercise intensities corresponding to 2.5 and $4.0 \mathrm{mmol} \cdot \mathrm{l}^{-1}$ blood lactate concentration in the three groups

\begin{tabular}{|c|c|c|c|}
\hline Lactate variable & Prepubertal & Teenage & Adult \\
\hline $\begin{array}{l}\% \text { peak } \dot{\mathrm{VO}}{ }_{2} \text { at } \\
2.5 \mathrm{mmol} \cdot \mathrm{I}^{-1 *}\end{array}$ & $85(6)$ & $85(9)$ & $80(9)$ \\
\hline $\begin{array}{l}\dot{\mathrm{VO}_{2}}\left(1 \cdot \mathrm{min}^{-1}\right) \text { at } \\
2.5 \mathrm{mmol} \cdot \mathrm{l}^{-1 *}\end{array}$ & $1.59(0.15)^{\mathrm{a}}$ & $2.25(0.47)^{b}$ & $3.43(0.62)$ \\
\hline $\begin{array}{l}\dot{\mathrm{VO}}_{2}\left(\mathrm{ml} \cdot \mathrm{kg}^{-1} \cdot \mathrm{min}^{-1}\right) \\
\text { at } 2.5 \mathrm{mmol} \cdot \mathrm{l}^{-1 *}\end{array}$ & $46(5)$ & $45(5)$ & $45(6)$ \\
\hline $\begin{array}{l}\% \text { peak } \dot{\mathrm{VO}}_{2} \text { at } \\
4.0 \mathrm{mmol} \cdot \mathrm{I}^{-1} \mathrm{t}\end{array}$ & $94(3)^{c}$ & $92(6)^{c}$ & $87(9)$ \\
\hline $\begin{array}{l}\dot{\mathrm{VO}_{2}}\left(1 \cdot \mathrm{min}^{-1}\right) \text { at } \\
4.0 \mathrm{mmol} \cdot \mathrm{l}^{-1}+\end{array}$ & $1.77(0.16)^{a}$ & $2.43(0.53)^{b}$ & $3.68(0.59)$ \\
\hline $\begin{array}{l}\dot{\mathrm{VO}_{2}}\left(\mathrm{ml} \cdot \mathrm{kg}^{-1} \cdot \mathrm{min}^{-1}\right) \\
\text { at } 4.0 \mathrm{mmol} \cdot \mathrm{l}^{-1} \mathrm{t}\end{array}$ & $51(5)$ & $49(6)$ & $48(6)$ \\
\hline
\end{tabular}

All values are mean(s.d.).

${ }^{*} n=21$ prepubertal boys, 22 teenage boys, and 18 men; $t n=17$ prepubertal boys, 21 teenage boys, and 21 men; ${ }^{\text {SSignificantly }}$ different from teenage and adult groups $(P<0.05)$; 'Significantly different from prepubertal and adult groups $(P<0.05)$;

'Significantly different from adult group $(P<0.05)$.

Table 3. Heart rate response at exercise intensities corresponding to 2.5 and $4.0 \mathrm{mmol} \cdot \mathrm{l}^{-1}$ blood lactate concentration in the three groups

\begin{tabular}{|c|c|c|c|}
\hline Lactate variable & Prepubertal & Teenage & Adult \\
\hline $\begin{array}{l}\% \text { peak HR at } \\
2.5 \mathrm{mmol} \cdot 1^{-1 *}\end{array}$ & $95(3)$ & $94(4)$ & $87(4)^{a}$ \\
\hline $\begin{array}{l}\mathrm{HR} \text { (beats } \cdot \min \text { ) at } \\
2.5 \mathrm{mmol} \cdot \mathrm{I}^{-1 *}\end{array}$ & $191(7)$ & 188(9) & $169(11)^{\mathrm{a}}$ \\
\hline $\begin{array}{l}\% \text { peak HR at } \\
4.0 \mathrm{mmol} \cdot 1^{-1}+\end{array}$ & $98(2)$ & $98(2)$ & $92(4)^{a}$ \\
\hline $\begin{array}{l}\text { HR (beats } / \mathrm{min} \text { ) at } \\
4.0 \mathrm{mmol} \cdot \mathrm{l}^{-1} t\end{array}$ & 199(5) & 199(9) & $179(10)^{\mathrm{a}}$ \\
\hline
\end{tabular}

All values are mean(s.d.).

${ }^{*} n=21$ prepubertal boys, 22 teenage boys, and 18 men; $t n=17$ prepubertal boys, 21 teenage boys, and 21 men; ' Significantly different from prepubertal and teenage groups $(P<0.05)$. 
and $18 \mathrm{men}$. At $4.0 \mathrm{mmol} \cdot \mathrm{l}^{-1}$ lactate, analysis was based upon 17 prepubertal boys, 21 teenage boys, and 21 men.

Mean percent $\dot{\mathrm{VO}}_{2}$ at the $2.5 \mathrm{mmol} \cdot \mathrm{l}^{-1}$ level (Table 2) was not significantly different across the three age groups $(P>0.05)$. Both groups of boys had significantly lower $(P<0.05)$ absolute $\mathrm{VO}_{2}\left(1 \cdot \mathrm{min}^{-1}\right)$ values than the men; the prepubertal group values were also significantly lower $(P<0.05)$ than the teenage group at the $2.5 \mathrm{mmol} \cdot 1^{-1}$ level. Body mass related $\mathrm{VO}_{2}$ $\left(\mathrm{ml} \cdot \mathrm{kg}^{-1} \cdot \mathrm{min}^{-1}\right)$ at $2.5 \mathrm{mmol} \cdot \mathrm{l}^{-1}$ lactate was not significantly different between the three groups $(P>0.05)$.

For both groups of boys $4.0 \mathrm{mmol} \cdot \mathrm{l}^{-1}$ lactate occurred at a significantly $(P<0.05)$ higher mean \% peak $\mathrm{VO}_{2}$ than in the men. The prepubertal and teenage values were not significantly different $(P>0.05)$. The prepubertal and teenage boys had lower absolute $\dot{\mathrm{VO}}_{2}$ values $(P<0.05)$ than the men at the $4.0 \mathrm{mmol} \cdot \cdot^{-1}$ level; the prepubertal group values were also significantly lower $(P<0.05)$ than the teenage group. Body mass related $\mathrm{VO}_{2}$ between age groups at $4.0 \mathrm{mmol} \cdot \mathrm{l}^{-1}$ lactate was not significantly different $(P>0.05)$.

Both groups of boys showed higher mean absolute heart rate and \% peak heart rate $(P<0.05)$ than the men at the 2.5 and $4.0 \mathrm{mmol} \cdot \mathrm{l}^{-1}$ lactate levels. The prepubertal and teenage values were not significantly different $(P>0.05)$. Correlation coefficients between peak $\dot{\mathrm{VO}}{ }_{2}\left(\mathrm{ml} \cdot \mathrm{kg}^{-1} \cdot \mathrm{min}^{-1}\right)$ and \% peak $\dot{\mathrm{VO}}_{2}$ at the 2.5 and $4.0 \mathrm{mmol} \cdot \mathrm{l}^{-1}$ levels were not significantly different from zero $(P>0.05)$.

\section{Discussion}

Mean percent peak $\dot{\mathrm{VO}}$, values at both the 2.5 and $4.0 \mathrm{mmol} \cdot \mathrm{l}^{-1}$ fixed blood lactate reference values in the prepubertal and teenage groups concur with the findings from the sparse number of studies conducted to date. ${ }^{3}$ It is clear that boys are able to exercise at intensities close to those which elicit peak $\mathrm{VO}_{2}$ without accumulating high levels of blood lactate. Submaximal lactate indices can be reliably reproduced given subjects who have had a period of familiarization with all test procedures. ${ }^{13}$

For some subjects interpolation at one, or both, of the lactate values was not possible. Lactate values for 13 subjects (nine prepubertal and four teenage) were lower than $4.0 \mathrm{mmol} \cdot \mathrm{l}^{-1}$ throughout the test. Furthermore, four prepubertal boys failed to reach a $2.5 \mathrm{mmol} \cdot \mathrm{l}^{-1}$ lactate value. An explanation for these low lactate responses is not clear. All subjects satisfied the criteria for maximum effort, ${ }^{10}$ so less than maximal effort is not a plausible explanation. Large between-subject variance in blood lactate responses to incremental exercise may partially explain this finding. One teenage boy and two men had lactate values that were above $4.0 \mathrm{mmol} \cdot \mathrm{l}^{-1}$ throughout the test. In addition, one prepubertal boy, four teenage boys and five men had lactate values above $2.5 \mathrm{mmol} \cdot \mathrm{l}^{-1}$ throughout the test. The most plausible explanation for these responses is an exaggerated, anxiety provoked catecholamine response at the onset of exercise. The relationship between adrenaline and glycolysis, with subsequent lactate accumulation, is well documented in both children and adults. ${ }^{14-16}$ These results suggest that the $4.0 \mathrm{mmol} \cdot \mathrm{l}^{-1}$ value may represent an inappropriate submaximal reference point for monitoring and assessing endurance performance in prepubertal and teenage boys, at least where a whole blood lactate assay is used. It is unlikely that prepubertal and teenage boys would be able to sustain exercise that corresponds to a $4.0 \mathrm{mmol} \cdot 1^{-1}$ fixed lactate for a period of time common to endurance events. Such a high lactate concentration would soon lead to exercise cessation in these groups.

The results of the limited number of child based studies indicate that the blood lactate response to submaximal exercise may be age or maturity related. ${ }^{2717}$ As no significant differences between the prepubertal and teenage boys were found in $\%$ peak $\mathrm{VO}_{2}$, body mass related peak $\dot{\mathrm{VO}}\left(\mathrm{ml} \cdot \mathrm{kg}^{-1} \cdot \mathrm{min}^{-1}\right)$, heart rate, and $\%$ peak heart rate at either the 2.5 or the $4.0 \mathrm{mmol} \cdot \mathrm{l}^{-1}$ lactate level this hypothesis is not supported. When expressed in terms of absolute peak $\dot{\mathrm{VO}} 2\left(\mathrm{l} \cdot \mathrm{min}^{-1}\right)$ the significant differences between the two groups of boys were to be expected due to the well documented increases in peak $\dot{\mathrm{VO}}_{2}$ with increasing body mass. ${ }^{18}$

That the $4.0 \mathrm{mmol} \cdot \mathrm{l}^{-1}$ blood lactate level corresponds to a significantly lower \% peak $\dot{\mathrm{VO}}_{2}$ \% peak heart rate, and absolute heart rate in the men as compared to both groups of boys reaffirms previous findings. ${ }^{24}$ When considering the heart rate responses that correspond to fixed blood lactate concentrations, children's hearts respond in a dissimilar manner to adults during submaximal exercise. This difference could be attributed to higher heart rate and lower stroke volume at each level of cardiac output compared to adults. ${ }^{19}$ Thus, lactate responses expressed in relation to heart rate at submaximal exercise must be viewed with caution when comparing children and adults. Possible explanations for the child-adult differences remain at present speculative. As differences at both the 2.5 and $4.0 \mathrm{mmol} \cdot 1^{-1}$ reference values between the two groups of boys were not demonstrated in this study, variations may not simply be ascribed to maturation. Child-adult differences in exercising blood lactate may be due to a lower muscle lactic acid production ${ }^{8}$ although, more recently, studies using radioactive isotope tracers to measure lactate turnover have indicated that this may only partly explain the differences. ${ }^{2021}$ As these studies involved adult subjects and not children, it may not be possible simply to extrapolate these results to paediatric populations. Research has shown that children may have an enhanced ability to derived energy aerobically as compared to adults. ${ }^{2223}$ It has also been suggested that the mediating role of catecholamine concentration on lactate response to exercise is different in children compared to adults. ${ }^{14}$ These differences may lead to preferential use of aerobic energy systems and a blunted catecholamine response resulting in a lower lactate production.

The finding that the $2.5 \mathrm{mmol} \cdot \mathrm{l}^{-1}$ lactate level represented a similar mean percent peak $\mathrm{VO}_{2}$ for each group is in contrast to previous reports. ${ }^{3717}$ Although further statistical analyses revealed strong trends when comparing the prepubertal and the adult groups (effect size $=0.66$ ), and the teenage and adult groups (effect 
size $=0.56)$ at the $2.5 \mathrm{mmol} \cdot \mathrm{l}^{-1}$ level; the nonsignificant findings at $P>0.05$ were accepted due to the strong power of the study. ${ }^{24}$

In conclusion, unlike men, prepubertal and teenage boys are able to exercise at intensities close to those which elicit peak $\mathrm{VO}_{2}$ without accumulating high levels of blood lactate. Conversely, the exercise intensity corresponding to the $2.5 \mathrm{mmol} \cdot \mathrm{l}^{-1}$ lactate concentration results in a similar \% peak $\mathrm{VO}_{2}$ in prepubertal boys, teenage boys and men. Factors other than maturation appear to influence whole blood lactate responses to exercise. Why physiological responses corresponding to blood lactate were different when comparing the boys and men at the higher exercise intensity and not the lower intensity is unknown. These results should be taken into account when considering physiological variables corresponding to fixed blood lactate concentrations to monitor and assess prepubertal and teenage boys' endurance performance.

\section{References}

1 Jacobs I. Blood lactate: implications for training and sports performance. Sports Med 1986; 1: 10-25.

2 Tanaka $H$, Shindo $M$. Running velocity at blood lactate threshold of boys aged 6-15 years compared with untrained and trained young males. Int J Sports Med 1985; 6: 90-4.

3 Williams JR, Armstrong N. Relationship of maximal lactate steady state to performance at fixed blood lactate reference values in children. Ped Exerc Sci 1991; 3: 333-41.

4 Atomi Y, Fukunaga T, Hatta H, Yamamoto Y. Relationship between lactate threshold during running and relative gastrocnemius area. J Appl Phys 1987; 63: 2343-47.

5 Williams JR, Armstrong N, Kirby BJ. The influence of the site of sampling and assay medium upon the measurement and interpretation of blood lactate responses to exercise. J Sports Sci 1992; 10: 95-107.

6 Tanner JM. Growth at adolescence, 2nd ed. Oxford, UK: Blackwell, 1962.

7 Wirth A, Trager E, Scheele K, Mayer D, Diehm K, Reisch K Weicker K. Cardiopulmonary adjustment and metabolic response to maximal and submaximal physical exercise of boys and girls at different stages of maturity. Eur J Appl Physiol 1978; 39: 229-40.
8 Eriksson BO, Karlsson J, Saltin B. Muscle metabolites during exercise in pubertal boys. Acta Paediatr Scand 1971; 217 (Suppl): 154-57.

9 Hale T, Armstrong N, Hardman A, Jakeman P, Sharp C, Winter E. Position Statement on the Physiological Assessment of the Elite Competitor. British Association of Sports Sciences, Leeds, 1988.

10 Sheehan JM, Rowland TW, Burke EJ. A comparison of four treadmill protocols for determination of maximum oxygen uptake in 10-12 year old boys. Int J Sports Med 1987; 8: 31-4.

11 Rivera-Brown AM, Rivera MA, Frontera WR. Applicability of criteria for $\mathrm{VO}_{2}$ max in active adolescents. Ped Exerc Sci 1992; 4 331-39.

12 Thomas JR, Nelson JK. Research methods in physical activity, 2nd ed. Champaign, Illinois, USA: Human Kinetics Books, 1990, pP 189-91.

13 Williams JR. The blood lactate response to exercise in children aged 11 to 16 years with reference to cardiorespiratory variables, chronological age, sex, sexual maturity and habitual physical activity. University of Exeter, Exeter, UK: Unpublished PhD thesis, 1990

14 Macek M. Aerobic and anaerobic energy output in children. In : J Rutenfranz, R Mocellin, F Klimt (eds.) Children and exercise XII. Champaign, Illinois, USA: Human Kinetics Books, 1986, pp 3-9.

15 Mazzeo RS, Marshall P. Influence of plasma catecholamines on the lactate threshold during graded exercise. J Appl Physiol 1989; 67: 1319-22.

16 Stainsby WN, Brooks GA. Control of lactic acid metabolism in contracting muscles and during exercise. Exerc Sport Sci Rev 1990; 18: $29-63$

17 Eriksson BO, Saltin B. Muscle metabolism during exercise in boys aged 11-16 years compared to adults. Acta Paediatr Belg 1974; 28 (Suppl): 257-65

18 Krahenbuhl GS, Skinner JS, Kohrt WM. Developmental aspects of maximal aerobic power in children. Exerc Sport Sci Rev 1985; 13: 503-38.

19 Bar-Or O. Pediatric sports medicine for the practitioner: from physiologic principles to clinical applications. New York, USA: Springer Verlag, 1983

20 Stanley WC, Lehman SL. A model for measurement of lactate disappearance with isotopic tracers in the steady state. Biochem J 1988; 256: 1035-38.

21 Brooks GA. Current concepts in lactate exchange. Med Sci Sports Exerc 1991; 23 : 895-906.

22 Berg A, Kim SS, Keul J. Skeletal muscle enzyme activities in healthy young subjects. Int J Sports Med 1986; 7: 236-39.

23 Fournier MJ, Ricci J, Taylor AW, Ferguson RJ, Montpetit RR, Chaitman BR. Skeletal muscle adaptation in adolescent boys: sprint and endurance training and detraining. Med Sci Sports Exerc $1982 ; 14: 453-56$.

24 Cohen J. Statistical power analysis for the behavioral sciences, 2nd ed. Hillsdale NJ, USA: Erlbaum, 1988. 